\title{
CFD analysis for effects of the crucible geometry on melt convection and growth behavior during sapphire single crystal growth by Kyropoulos process
}

\author{
J.H. Ryu, W.J. Lee, Y.C. Lee*, H.H. Jo* and Y.H. Park ${ }^{\dagger}$ \\ Department of Materials Science and Engineering, Pusan National University, Busan 609-735, Korea \\ *Dongnam Technology Service Division, Korea Institute of Industrial Technology, Busan 618-230, Korea \\ (Received May 24, 2012)
}

(Revised June 8, 2012)

(Accepted June 12, 2012)

\begin{abstract}
Sapphire single crystals have been highlighted for epitaxial gallium nitride films in high-power laser and light emitting diode (LED) industries. Among the many crystal growth methods, the Kyropoulos process is an excellent commercial method for growing larger, high-optical-quality sapphire crystals with fewer defects. Because the properties and growth behavior of sapphire crystals are influenced largely by the temperature distribution and convection of molten sapphire during the manufacturing process, accurate predictions of the thermal fields and melt flow behavior are essential to design and optimize the Kyropoulos crystal growth process. In this study, computational fluid dynamic simulations were performed to examine the effects of the crucible geometry aspect ratio on melt convection during Kyropoulos sapphire crystal growth. The results through the evolution of various growth parameters on the temperature and velocity fields and convexity of the crystallization interface based on finite volume element simulations show that lower aspect ratio of the crucible geometry can be helpful for the quality of sapphire single crystal.
\end{abstract}

Key words Computer simulation, Convection, Radiation, Single crystal growth, Kyropoulos method, Sapphire

\section{사파이어 단결정의 Kyropoulos 성장시 도가니 형상에 따른 유동장 및 결정성장 거동의 CFD 해석}

\author{
류진호, 이욱진, 이영철*, 조형호*, 박용호 \\ 부산대학교 재료공학부, 부산, 609-735 \\ *한국생산기술연구원, 부산, 618-230 \\ (2012년 5월 24일 접수) \\ (2012년 6월 8일 심사완료) \\ (2012년 6월 12일 게재확정)
}

요 약 사파이어 단결정은 $\mathrm{GaN}$ 계 화합물 증착이 용이하여 고휘도의 청색을 구현하기 위한 $\mathrm{LED}(\mathrm{Light}$ Emitting Diode) 용 기판으로 크게 각광받고 있다. 공업용 사파이어의 제조 방법으로는 Kyropoulos법, Czochralski법 HEM(Heat Exchager Method)등 다양한 방법이 시도되고 있으며, 그 중 Kyropoulos법은 고품질의 대구경 사파이어 단결정 성장이 가능한 대표적 인 방법으로 알려져 있다. 그러나 Kyropoulos 공정의 특성상 결정성장로 내에서 용융 사파이어의 유동장이 단결정의 최종 품질을 결정하는데, 유동장의 변화와 이에 따르는 결정성장 거동을 관찰하기가 어렵다는 단점이 있다. 대구경화와 동시에 고품질의 사파이어 단결정을 생산하기 위해서는 성장로내의 유동장 해석을 통해 결정 성장조건을 최적화 하는 것이 필요 하다. 본 연구에서는 유한요소법을 기반으로 한 전산유동해석을 통해 Kyropoulos 성장로 내의 도가니 형상의 종횡비(h/d)에 따른 용융 사파이어의 대류거동을 관찰하여 도가니의 형상이 단결정 성장에 미치는 영향을 분석하였으며, 성장로의 설계 시 도가니의 종횡비를 작게 고려하면 용융 사파이어의 대류속도를 늦추고 계면의 convexity를 줄여 사파이어 단결정의 품 질향상에 도움이 된다는 결과를 얻었다.

\footnotetext{
Corresponding author

Tel: +82-51-510-2851

Fax: +82-51-514-4457

E-mail: yhpark@pusan.ac.kr
} 


\section{1. 서 론}

사파이어 단결정은 높은 강도와 함께 뛰어난 광 투과 성 및 열전도도, 내부식성 등의 장점을 가지며, 이로 인 해 극한의 환경에서도 견디는 고 투과성 window와 같 은 특수 목적뿐만 아니라 의료용 칼, 바코드 기판, 고성 능 베어링 등 다양한 분야에 걸쳐 사용되고 있다. 특히 최근 들어 수요가 급격하게 증가되고 있는 Light emitting $\operatorname{diode}(\mathrm{LED})$ 산업에서 $\mathrm{GaN}$ 계 화합물 증착이 용이하여 고휘도의 청색을 구현하기 위한 기판소재로 크게 각광받 고 있다[1,2].

사파이어 단결정을 LED 기판 재료로 사용하기 위해 서는 내부결함이 적은 고품질의 잉곳을 제조하는 기술이 필수적이며, 생산성 확보를 위한 대구경화도 함께 이루 어져야 한다. LED 기판용 사파이어 잉곳 제조 방법은 아직까지 정형화되어 있지 않고, 제조 방법이 유사한 반 도체 기판용 단결정 잉곳의 제조법을 기반으로 다양한 방법들이 응용되고 있다. 단결정 잉곳의 성장 방법은 매 우 다양하지만, 대구경화가 용이하고 대량생산이 가능한 방법으로는 대표적으로 $\mathrm{HEM}[3], \mathrm{Kyropolos}(\mathrm{KY})[4]$ 및 Czocralski(CZ)[5] 등이 있다. 특히 반도체 기판 소재로 가장 널리 사용되는 $\mathrm{Si}$ 의 경우 대부분 $\mathrm{CZ}$ 법을 이용하여 단결정 잉곳을 생산하고 있다. 하지만 산화물 반도체인 사파이어는 $\mathrm{Si}, \mathrm{Ge}$ 등의 기존 금속기 반도체 기판소재에 비해 매우 높은 융점 $\left(\right.$ 약 $\left.2100^{\circ} \mathrm{C}\right)$ 으로 인해 성장로내 온 도가 매우 높고, 용융 산화물의 특성상 용탕의 점성계수 또한 크기 때문에 용탕의 유동에 의한 결함이 발생이 쉽 게 일어나기 때문에 $\mathrm{CZ}$ 법을 이용하여 고품질 잉곳을 얻기에는 제약이 따른다. 또한 $\mathrm{CZ}$ 법을 적용할 경우 성 장로 내부 온도 조절, seeding 및 rotating과 같은 주요 한 공정인자의 정밀제어에 어려움이 있으며, 회전과 끌 어올림 시 단결정 내부 열응력의 제어가 어렵기 때문에 잉곳을 대형화 하기 힘든 단점도 가지고 있다. 한편, $\mathrm{KY}$ 법은 $\mathrm{CZ}$ 과 유사하나, seed의 회전과 끌어올림이 없 이 seed load의 냉각을 유지하면서 성장로 내의 온도를 서서히 낮추어 단결정을 제조하는 결정성장법으로, 최근 $\mathrm{KY}$ 법을 통해 지름 $300 \mathrm{~mm}, 65 \mathrm{~kg}$ 급의 초 대구경 잉곳 을 제조하는데 성공한 사례가 보고되는 등, 현재까지 상 업적으로 응용되고 있는 공정 중 대구경 사파이어 잉곳 을 가장 효율적으로 생산 할 수 있는 방법으로 알려져 있다[6].

한 편, $\mathrm{KY}$ 성장로는 공정 특성상 열 차폐 및 분위기 조절을 위하여 겹겹이 둘러 쌓인 챔버 내부에서 결정 성 장이 진행되기 때문에 단결정의 온도분포나 용탕의 대류 거동 등 내부에서 발생하는 현상에 대한 정보가 제한적 이다. 따라서 성장로 내부의 현상을 이해하고 최적의 공 정인자를 확립하기 위해서 전산유체역학(computational fluid dynamic, CFD)를 통한 열, 유체 유동 및 성장거동 에 대한 시뮬레이션이 필수적이다[7,8]. 현재까지 Demina et al.[4], Chen et al.[9] and Lee et al.[7] 등 많은 연 구자들에 의해 $\mathrm{KY}$ 공정에 대한 시뮬레이션 연구가 이루 어졌으나, 대부분의 연구에서 모델은 특정 성장로의 성 장 거동에 초점이 맞추어져 있었다. 이와 같은 연구는 기존의 상업화된 $\mathrm{KY}$ 성장로를 분석하고 이를 통해 공 정인자를 설계하는 데 매우 유용할 것으로 판단되지만, 다양한 공정 조건 하에서의 유동장을 알아보고 최적화된 $\mathrm{KY}$ 성장로를 설계하기 위해서는 추가적으로 많은 연구 가 필요한 실정이다. 특히 $\mathrm{KY}$ 법을 통해 사파이어를 성 장시키는 경우 결정의 $\mathrm{A}$ 축으로 단결정을 성장시켜 $\mathrm{C}$ 축 방향으로 절단, 기판소재로 활용하기 때문에 최종 잉곳 의 크기 및 전체 성장로의 제조효율이 도가니의 종횡비 에 의해 크게 좌우되며, 또한 용탕의 유동 및 결정성장 거동 또한 도가니의 종횡비에 따라 달라지므로 도가니의 종횡비를 적절히 선택하는 것이 $\mathrm{KY}$ 성장로의 설계에 있어 필수적인 인자 중 하나이다. 따라서 본 연구에서는 전산유동해석을 통해 $\mathrm{KY}$ 성장로 내의 도가니의 종횡비 가 용융 사파이어의 대류거동과 고액계면의 성장거동에 미치는 영향을 분석하며, 이를 통해 $\mathrm{KY}$ 성장로 설계에 있어서 최적의 도가니 종횡비를 도출해내고자 하였다.

\section{2. 모델링}

시뮬레이션에 사용된 모델의 컨셉, 기하학적 형상 및 해석 격자를 Fig. 1에 나타내었다. 모델은 현재 상업적 으로 응용되고 있는 실제 $\mathrm{KY}$ 성장로의 형상을 참조하 여 실린더 형태의 텅스텐 도가니 주변이 텅스텐 재질의 열원으로 둘러 쌓여 있으며 열원의 외곽을 여러겹의 몰 리브덴 재질의 열차폐 쉴드로 감싼 형태의 성장로로 설

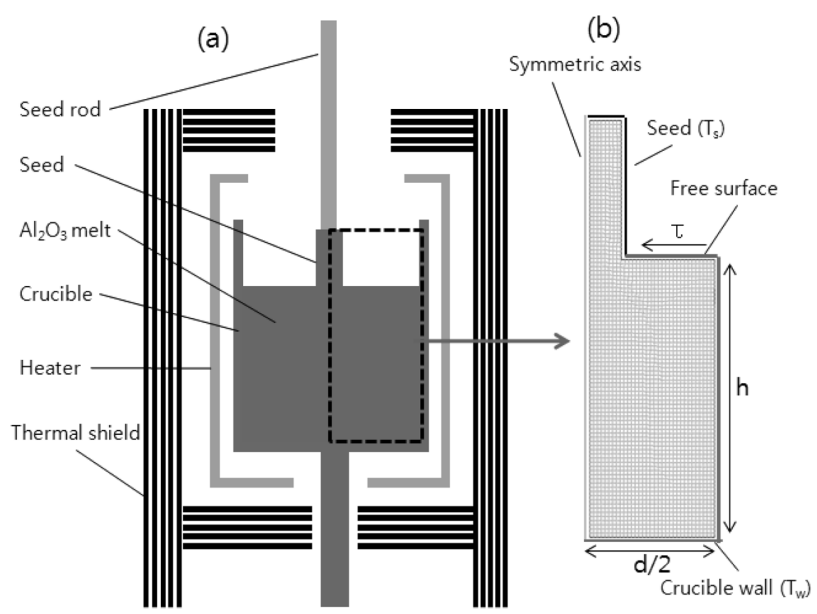

Fig. 1. Schematic of the crucible geometry in Kyropoulos growth system (a) and computational domain for the CFD simulations (b). 
계하였다. 용탕의 자유표면 중앙에 실린더 형태의 Seed 가 위치하는 형상으로 하였고, 해석의 중점을 도가니 종 횡비에 따른 용탕의 유동과 결정성장 거동에 두어 hot zone 내부만을 고려하여 모델링 하였다. 성장 중 Seed 윗부분은 수냉에 의해 일정한 온도를 유지한다고 가정하 여 seed를 통한 냉각이 일어나도록 하면서 도가니의 내 벽의 온도를 서서히 낮추어 가면서 결정성장 거동을 관 찰하였다. 도가니 내벽의 온도가 약 2332 2327 K 범위 에서 결정성장이 진행되는 과정을 시뮬레이션 하였으며, 고액 계면의 형상, 용탕의 온도분포 및 유동속도를 관찰 함으로써 도가니 형상의 종횡비가 고액 계면의 형상 및 유동장에 미치는 영향을 분석하였다. 또한 축대칭 (axisymmetric) 조건을 활용하여 2차원 모델로 단순화 하여 해석 결과의 직관적 분석 및 해석 효율화를 꾀하였 다. 도가니형상의 종횡비(h/d)에 따른 용탕의 거동과 고 액계면의 성장거동을 분석하기 위해 도가니의 종횡비를 각 $\mathrm{h} / \mathrm{d}=0.75,1.0,1.25,1.5$ 로 다르게 하여 총 4 가지 모델을 해석에 사용하였다. 단결정의 초기 응고부위와 최종 응고부위는 결함이 많고 품질이 떨어져서 상부와 하부의 일정 부분은 제품으로 사용되기에는 부적합하다. 따라서 잉곳의 회수율을 고려할 때 도가니의 종횡비를 0.75 1.5 범위로 하는 것이 적절하다. 이 때, 용융 $\mathrm{Al}_{2} \mathrm{O}_{3}$ 의 체적 변화에 따른 변수를 최소화 하기 위해 도가니의 부피는 $6.28 \times 10^{-3} \mathrm{~m}^{3}$ 으로 모두 일정하게 하였다. 실험 에 앞서 각 모델의 해석격자 크기가 수치적 연산에 적합 하도록 격자크기를 변화시켜 반복적인 해석을 수행하였 으며, 각 모델별로 약 6000 개의 요소 (해석격자 $3 \mathrm{~mm}$ ) 를 사용할 경우 충분한 수의 격자를 가지며 신뢰성 있는 해석결과를 나타내었기 때문에 본 실험에 적용하였다. 해석에 사용된 사파이어 및 용융 $\mathrm{Al}_{2} \mathrm{O}_{3}$ 의 물리, 광학적 재료물성들을 Table 1에 나타내었다. 해석 시 용융 $\mathrm{Al}_{2} \mathrm{O}_{3}$ 는 비압축성 점성유체 거동을 한다고 가정하였으며, 단 결정 및 용융 $\mathrm{Al}_{2} \mathrm{O}_{3}$ 모두 등방성을 가정하여 시뮬레이

Table 1

Physical properties of the aluminum oxide used in this study

\begin{tabular}{ll}
\hline Properties & Values \\
\hline Thermal conductivity of the crystal $\left(\mathrm{k}_{\mathrm{c}}, \mathrm{W} / \mathrm{m} \mathrm{K}\right)$ & 5 \\
Thermal conductivity of the melt $\left(\mathrm{k}_{\mathrm{m}}, \mathrm{W} / \mathrm{m} \mathrm{K}\right)$ & 2.05 \\
Specific heat $\left(\mathrm{C}_{\mathrm{p}}, \mathrm{J} / \mathrm{kg} \mathrm{K}\right)$ & 1430 \\
Density $\left(\rho, \mathrm{kg} / \mathrm{m}^{3}\right)$ & 3970 \\
Latent heat of solidification $(\Delta \mathrm{H}, \mathrm{J} / \mathrm{kg})$ & $1,407,000$ \\
Melting temperature $\left(\mathrm{T}_{\mathrm{m}}, \mathrm{K}\right)$ & 2327 \\
Dynamic viscosity $(\mu, \mathrm{kg} / \mathrm{m} \mathrm{S})$ & 0.057 \\
Thermal expansion coefficient $\left(\beta, \mathrm{K}^{-1}\right)$ & $1.8 \times 10^{-5}$ \\
Transparent band $(\mu \mathrm{m})$ & $0.5 \sim 4.5$ \\
Absorption coefficient $\left(\tilde{\mathrm{K}}, \mathrm{m}^{-1}\right)$ & 19.26 \\
Scattering coefficient $(\tilde{\sigma})$ & 0 \\
Refractive index $(\tilde{\eta})$ & 1.78 \\
\hline
\end{tabular}

션을 단순화하였다.

\section{1. 지배방정식}

본 연구에서 용융 $\mathrm{Al}_{2} \mathrm{O}_{3}$ 의 유동은 Navier-Stokes 식에 의해 결정된다고 가정하였으며, 해석에 쓰인 연속 방정 식, 운동량 방정식, 에너지 방정식은 각각 다음과 같다.

$$
\text { 연속방정식 } \frac{1}{\mathrm{r}} \cdot \frac{\partial}{\partial \mathrm{r}}\left(\mathrm{r} \cdot \mathrm{V}_{\mathrm{r}}\right)+\frac{\partial \mathrm{V}_{\mathrm{z}}}{\partial \mathrm{z}}=0
$$

$\mathrm{r}$-방향 운동량 방정식

$$
\begin{aligned}
\rho \cdot\left(\mathrm{V}_{\mathrm{r}}\right. & \left.\cdot \frac{\partial \mathrm{V}_{\mathrm{r}}}{\partial \mathrm{r}}+\mathrm{V}_{\mathrm{z}} \cdot \frac{\partial \mathrm{V}_{\mathrm{r}}}{\partial \mathrm{z}}\right)=-\frac{\partial \mathrm{P}}{\partial \mathrm{r}} \\
& +\mu \cdot\left[\frac{\partial}{\partial \mathrm{r}} \cdot\left(\frac{1}{\mathrm{r}} \cdot \frac{\partial}{\partial \mathrm{r}} \cdot\left(\mathrm{r} \cdot \mathrm{V}_{\mathrm{r}}\right)\right)+\frac{\partial^{2} \mathrm{~V}_{\mathrm{r}}}{\partial \mathrm{r}^{2}}\right]
\end{aligned}
$$

z-방향 운동량 방정식

$$
\begin{aligned}
\rho \cdot\left(\mathrm{V}_{\mathrm{r}} \cdot \frac{\partial \mathrm{V}_{\mathrm{z}}}{\partial \mathrm{r}}+\mathrm{V}_{\mathrm{z}} \cdot \frac{\partial \mathrm{V}_{\mathrm{z}}}{\partial \mathrm{z}}\right) \\
\quad=\mu \cdot\left[\frac{1}{\mathrm{r}} \cdot \frac{\partial}{\partial \mathrm{r}} \cdot\left(\mathrm{r} \cdot \frac{\partial \mathrm{V}_{\mathrm{z}}}{\partial \mathrm{r}}\right)+\frac{\partial^{2} \mathrm{~V}_{\mathrm{z}}}{\partial \mathrm{z}^{2}}\right]+\rho \cdot \beta \cdot \overrightarrow{\mathrm{g}} \cdot\left(\mathrm{T}-\mathrm{T}_{\mathrm{m}}\right)
\end{aligned}
$$

에너지 방정식

$$
\begin{aligned}
& \rho \cdot C_{P} \cdot\left(V_{r} \cdot \frac{\partial T}{\partial r}+V_{z} \cdot \frac{\partial T}{\partial z}\right)=k \cdot\left[\frac{1}{r} \cdot \frac{\partial}{\partial r} \cdot\left(r \frac{\partial T}{\partial r}\right)+\frac{\partial^{2} T}{\partial z^{2}}\right] \\
& \rho \cdot C_{P} \cdot \frac{d T}{d t}=k \cdot \Delta \cdot T-\nabla \cdot \vec{q}_{\mathrm{rad}}
\end{aligned}
$$

여기서 $\rho$ 는 밀도, $\mathrm{P}$ 는 압력, $\mathrm{C}_{\mathrm{p}}$ 는 비열, $\mathrm{T}_{\mathrm{m}}$ 용융온도, $\mathrm{t}$ 는 시간이다. $\mu, \overrightarrow{\mathrm{g}}, \beta$ 는 각각 동점성계수, 중력, 열팽창 계수를 나타내며, (5)식의 오른쪽 두 번째 항은 복사에 의한 열 전달량을 나타낸다.

\section{2. 경계조건}

본 연구에서는 텅스텐 히터에 의해 가열된 도가니의 바닥을 포함한 내벽의 온도구배는 없다고 가정하였으며, $\mathrm{KY}$ 성장시 도가니의 온도를 매우 서서히 떨어뜨리면서 결정성장이 진행되기 때문에 각 성장단계에서 용탕과 접 하는 도가니 내벽의 온도가 일정하다고 가정하였다.

$$
\mathrm{T}=\mathrm{Tw}
$$

결정성장이 진행되는 동안 Seed의 온도는 일정하게 유 지 된다고 가정하였다.

$$
\mathrm{T}=\mathrm{Ts}
$$

용탕의 자유표면은 평면으로 가정하였으며, 온도에 따른 
점성변화에 의한 표면장력 효과를 고려하였다. 자유표면 에서의 열전달은 대류나 전도에 의한 열전달이 복사열에 의한 열전달에 비해 무시할 만큼 작다고 가정하였다.

$$
\tau=\frac{\delta \sigma}{\delta \mathrm{T}} \nabla_{\mathrm{s}} \mathrm{T}
$$

식(8)는 용탕의 자유표면에서 Marangoni effect를 나 타낸다. $\delta \sigma / \delta \mathrm{T}$ 는 온도에 따른 표면장력 구배, $\nabla_{\mathrm{s}} \mathrm{T}$ 는 표 면의 온도구배를 나타낸다.

\section{3. 복사 열전달 모델}

일반적으로 산화물 반도체의 용탕은 점도가 높고 반 투명하기 때문에 복사에 의한 열 전달이 지배적이다. 본 연구에서는 반투명한 용융 $\mathrm{Al}_{2} \mathrm{O}_{3}$ 및 성장된 단결정 의 내부 복사 열 전달을 Discrete Ordinates(DO) 모델
을 통해 고려하였다. DO 모델은 복사에 의한 열 전달 을 유한개의 입체각으로 나누어 해를 추정하는 방법으 로[10] 유한개의 방향벡터 $\vec{S}$ 에 대해 다음과 같은 관계 를 가진다.

$$
\begin{aligned}
& \nabla \cdot\left(\mathrm{I}_{\lambda}(\overrightarrow{\mathrm{r}}, \overrightarrow{\mathrm{s}}) \cdot \overrightarrow{\mathrm{s}}\right)+\left(\tilde{\mathrm{k}}+\sigma_{\mathrm{s}}\right) \cdot \mathrm{I}_{\lambda}(\overrightarrow{\mathrm{r}}, \overrightarrow{\mathrm{s}}) \\
& \quad=\tilde{\mathrm{k}} \cdot \mathrm{n}^{2} \cdot \mathrm{I}_{\mathrm{b} \lambda}+\frac{\sigma_{\mathrm{s}}}{4 \pi} \cdot \int_{0}^{4 \pi} \mathrm{I}_{\lambda}\left(\overrightarrow{\mathrm{r}}, \overrightarrow{\mathrm{s}}^{\prime}\right) \Phi\left(\overrightarrow{\mathrm{s}}, \overrightarrow{\mathrm{s}}^{\prime}\right) \mathrm{d} \Omega^{\prime}
\end{aligned}
$$

여기서 $\mathrm{I}$ 는 $\overrightarrow{\mathrm{r}}$ 와 $\overrightarrow{\mathrm{S}}$ 에 의존하는 복사강도, $\tilde{\mathrm{k}}$ 는 흡수계 수, $\sigma_{\mathrm{s}}$ 는 산란계수, $\mathrm{n}$ 는 굴절률, $\Phi$ 는 위상함수, $\Omega$ 는 입 체각, $\mathrm{I}_{\mathrm{b} \lambda}$ 는 Planck에 의해 주어지는 흑체 복사 강도를 나타낸다.

해석은 상용프로그램인 Fluent[11]를 이용하여 수행하 였으며, SIMPLE(Semi-Implicit Method for PressureLinked Equations) 알고리즘과 PRESTO(PREssure STaggering Option) scheme을 해석에 적용하였다.

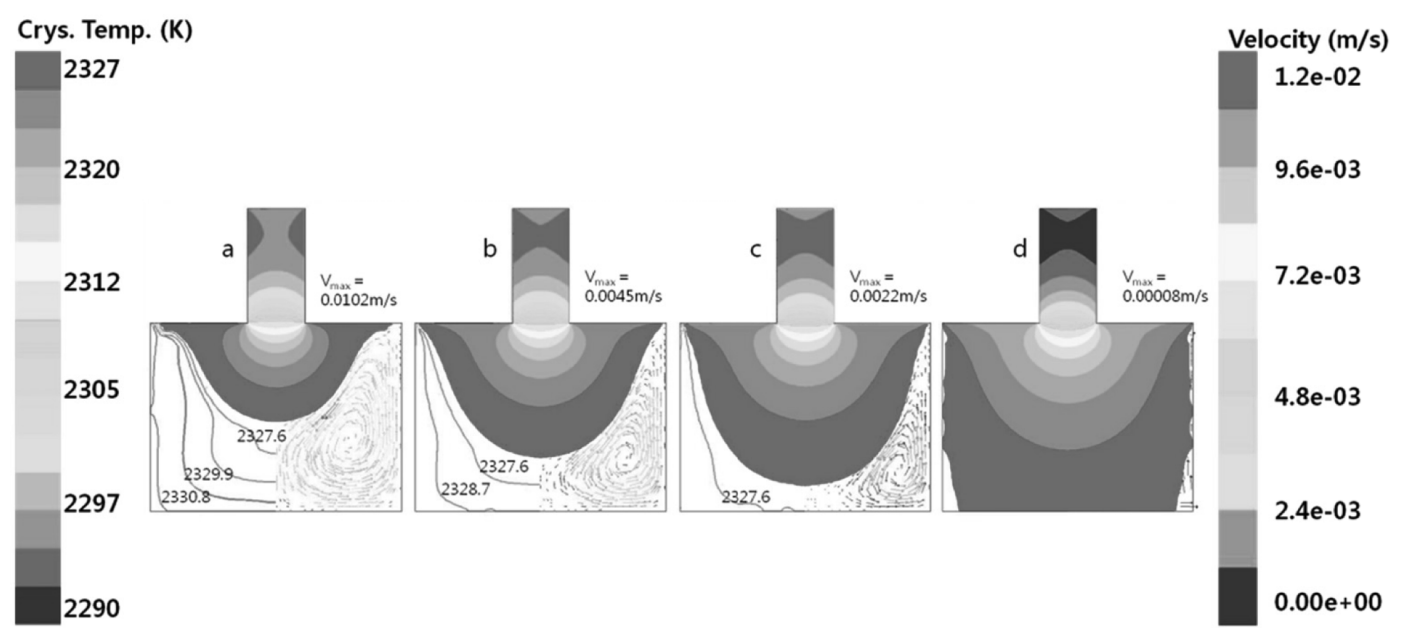

Fig. 2. Predicted evolution of temperature distributions (left-hand side), maximum velocity magnitudes (right-hand side) with crystal shape for different aspect ratios of the crucible geometry during KY growth: $(\mathrm{a} \sim \mathrm{d}) \mathrm{h} / \mathrm{d}=0.75$.
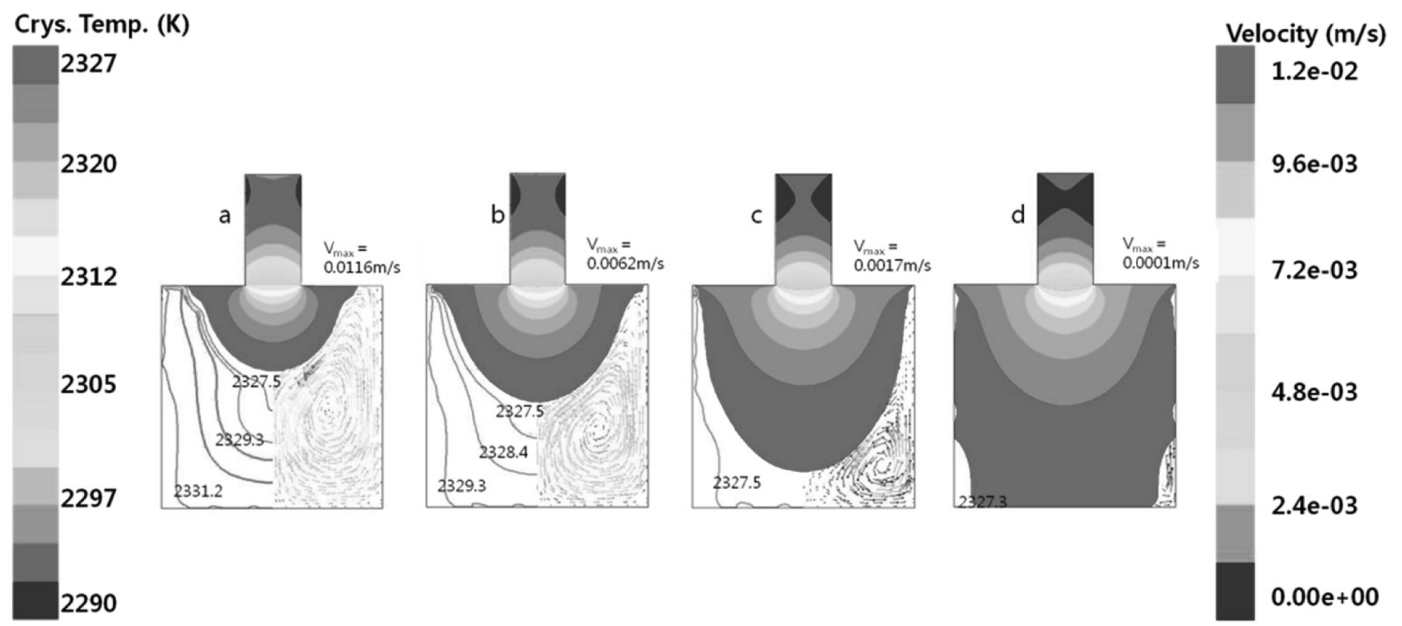

Fig. 3. Predicted evolution of temperature distributions (left-hand side), maximum velocity magnitudes (right-hand side) with crystal shape for different aspect ratios of the crucible geometry during KY growth: (a d) $h / d=1.0$. 


\section{3. 결과 및 고찰}

Fig. 2 5까지 도가니의 종횡비 $(\mathrm{h} / \mathrm{d}=0.75 \sim 1.5)$ 에 따른 각 모델의 결정성장 계면의 형상과 함께 왼쪽에는 용탕 의 온도분포, 오른쪽에는 계면에서의 최고 유동 속도를 표시하였으며, 각 Fig.의 (a) (d) 순서로 도가니 내벽의 온도 감소에 따라 결정성장이 진행되는 단계를 나타내었 다. 전체적인 결정성장 형태를 살펴보면 성장 초기에는 (각 Fig.의 (a) (b)) 도가니의 종횡비에 관계없이 도가니 내벽의 온도 감소에 따라 수평방향으로 결정성장이 진행 되다가 계면이 도가니 내벽과 가까워질수록 아래쪽으로 성장이 진행되는 것을 관찰할 수 있다.

중기 이후의 성장거동을 보면 $\mathrm{h} / \mathrm{d}$ 가 1 이하인 경우도 가니의 바닥까지 결정성장이 진행되면서 도가니 내벽까 지의 응고는 가장 늦게 일어나는 반면(Fig. 2(c), (d), Fig. 3(c), (d)), h/d가 1보다 큰 모델은 도가니 내벽으로
결정성장이 진행 되고 도가니 바닥으로 응고가 진행되는 형태를 보였다(Fig. 4(c), (d), Fig. 5(c), (d)), 이는 도가 니 내벽과 seed 사이의 냉각 거리에 따라 용탕 내의 온 도 분포가 달라지기 때문이며, 결과적으로 중기 이후 용 융 $\mathrm{Al}_{2} \mathrm{O}_{3}$ 의 유동과 결정성장 거동에 영향을 미치는 것 으로 판단된다.

도가니 내의 용융 $\mathrm{Al}_{2} \mathrm{O}_{3}$ 의 흐름은 도가니의 형상과 관계없이 모든 모델에서 큰 하나의 소용돌이가 형성됨을 확인할 수 있으며, 성장로 내 유동 거동은 중력 및 용융 $\mathrm{Al}_{2} \mathrm{O}_{3}$ 의 밀도 차에 의한 자연대류(Buoyancy flow)가 지 배적인 것으로 판단된다. 도가니의 형상에 따라 도가니 의 종횡비가 작을 때는 소용돌이의 형태가 원에 가까웠 으며, 종횡비가 커질수록 도가니의 길이 방향으로 길쭉 한 형태로 변하였다. 무차원 상수인 Grashof Number $(\mathrm{Gr}), \mathrm{Gr}=\beta \cdot \rho^{2} \cdot \mathrm{L}^{3} \cdot \Delta \mathrm{T} / \mu^{2}$ 는 자연대류에서 유체의 층 난류 거동을 확인하는 지표로 활용 되는데[12], 본 실험
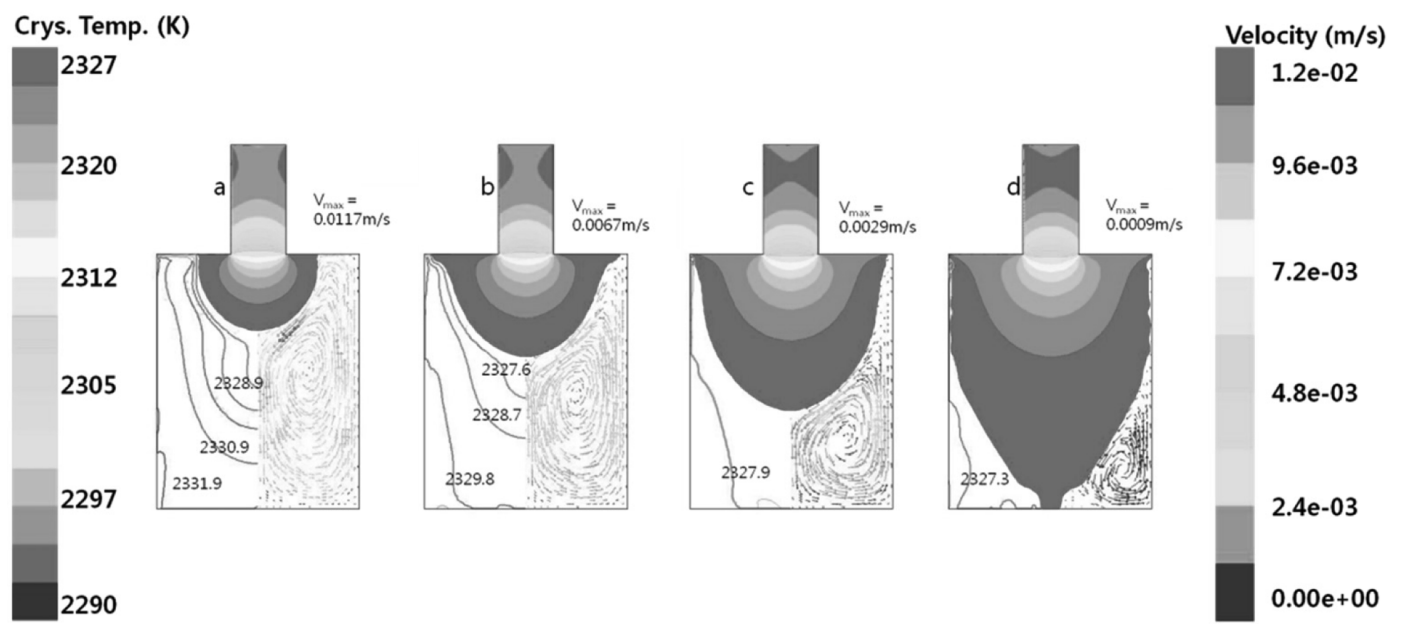

Fig. 4. Predicted evolution of temperature distributions (left-hand side), maximum velocity magnitudes (right-hand side) with crystal shape for different aspect ratios of the crucible geometry during KY growth: (a d) $h / d=1.25$.
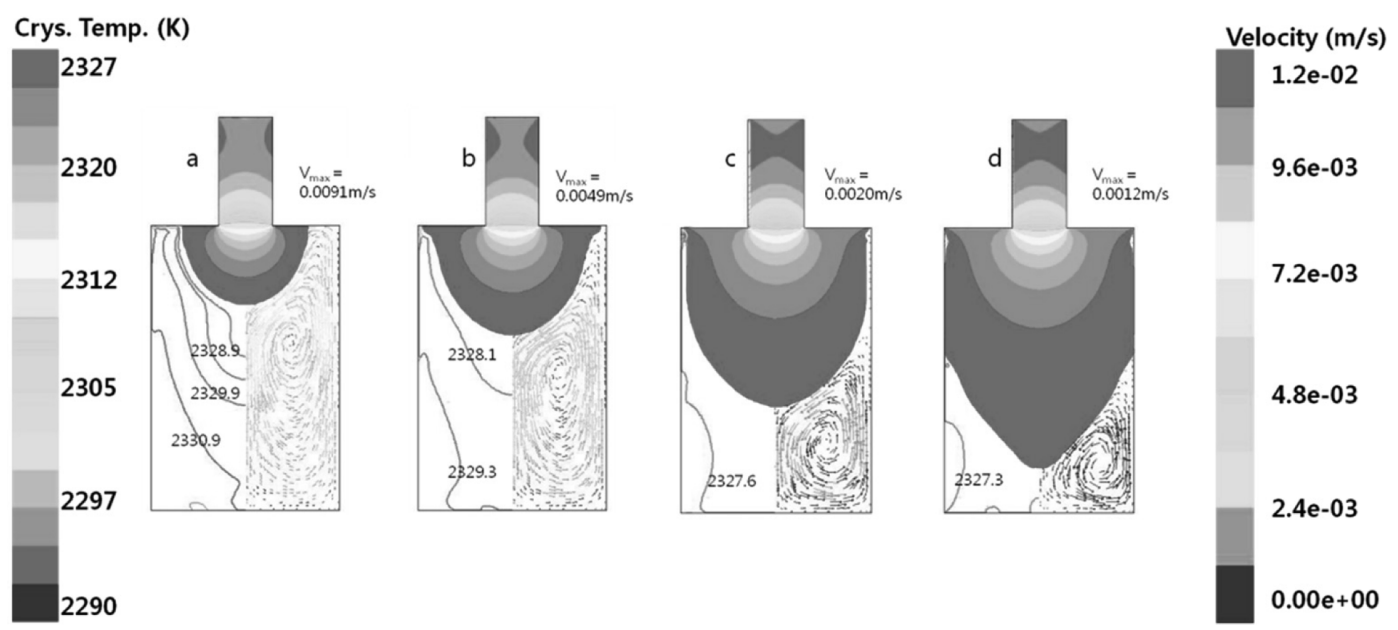

Fig. 5. Predicted evolution of temperature distributions (left-hand side), maximum velocity magnitudes (right-hand side) with crystal shape for different aspect ratios of the crucible geometry during KY growth: (a d) $h / d=1.5$. 


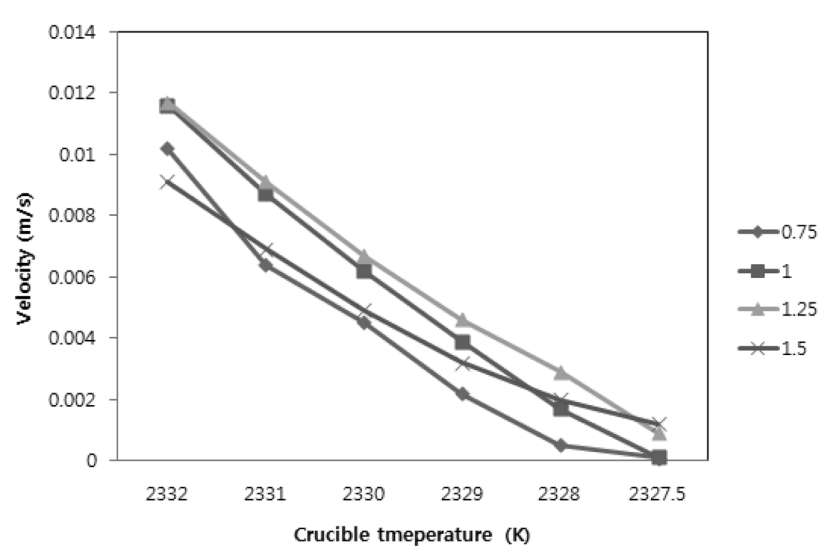

Fig. 6. Evolution of maximum velocity with temperature of the crucible wall.

에서는 모든 모델에 대해 수직방향 $3.0 \mathrm{E}+04$ 이하, 수평 방향 $1.5 \mathrm{E}+03$ 이하로 매우 낮은 값을 가져, 결정성장이 진행되는 동안 성장로 내 용융 $\mathrm{Al}_{2} \mathrm{O}_{3}$ 의 흐름이 층류로 유지됨을 예측할 수 있었다.

각 모델의 용융 $\mathrm{Al}_{2} \mathrm{O}_{3}$ 최대 유동속도를 Fig. 6에 나타 내었다. 도가니의 형상과는 무관하게 용융 $\mathrm{Al}_{2} \mathrm{O}_{3}$ 의 최대 속도는 결정성장 계면 부근에서 나타났으며, 결정계면 부근에서의 유동속도가 사파이어 단결정의 품질에 영향 을 주기 때문에 각 모델에 대해 최대 유동 속도를 비교 하였다. 모든 모델에서 유동 속도는 결정이 성장 하면서 선형적으로 감소하였는데, 이는 도가니 내벽의 온도 감 소에 따라 대류 구동력이 줄어듦과 동시에 성장이 진행 되며 용융 $\mathrm{Al}_{2} \mathrm{O}_{3}$ 의 체적 역시 감소하기 때문으로 판단 된다. 그리고 $\mathrm{h} / \mathrm{d}=1.25$ 인 모델은 결정이 성장되는 동안 다른 모델들에 비해 빠른 유동 속도를 유지하였으며, $\mathrm{h} /$ $\mathrm{d}=0.75$ 인 모델에서 유동속도가 가장 느린 결과를 관찰 할 수 있다. 이는 $\mathrm{h} / \mathrm{d}$ 가 1.25 에 가까울수록 용탕 내부의 수평방향 및 수직방향의 온도구배가 크고 소용돌이가 구 형에 가깝게 형성되어 용탕 흐름의 구동력이 커지기 때 문으로 생각된다. $\mathrm{KY}$ 성장 공정에서 단결정/용융 $\mathrm{Al}_{2} \mathrm{O}_{3}$ 계면 부근의 유동 속도가 빠르게 되면 점성에 의해 전단 응력이 부가되어 성장된 단결정의 전위밀도가 높아질 수 있기 때문에 일반적으로 유동 속도를 느리게 하는 것이 유리하다고 알려져 있다.

한편, 유동속도와 더불어 $\mathrm{KY}$ 공정에서 성장 중 결정 성장 계면의 뾰족한 정도(convexity) 역시 최종 단결정 의 품질에 많은 영향을 미치는 인자로 알려져 있는데, 이는 성장중단결정/용융 $\mathrm{Al}_{2} \mathrm{O}_{3}$ 계면이 뾰족한 모양을 띨 수록 단결정 내부의 온도구배가 극심하며 따라서 최종적 으로 성장된 단결정의 전위밀도에 악영향을 미치기 때문 이다. 계면의 뾰족한 정도를 정량적으로 분석하기 위해 서는 주로 Chen[13] 이 제안한 convexity(D) 지표를 주 로 활용하며, 다음과 같이 정의된다.

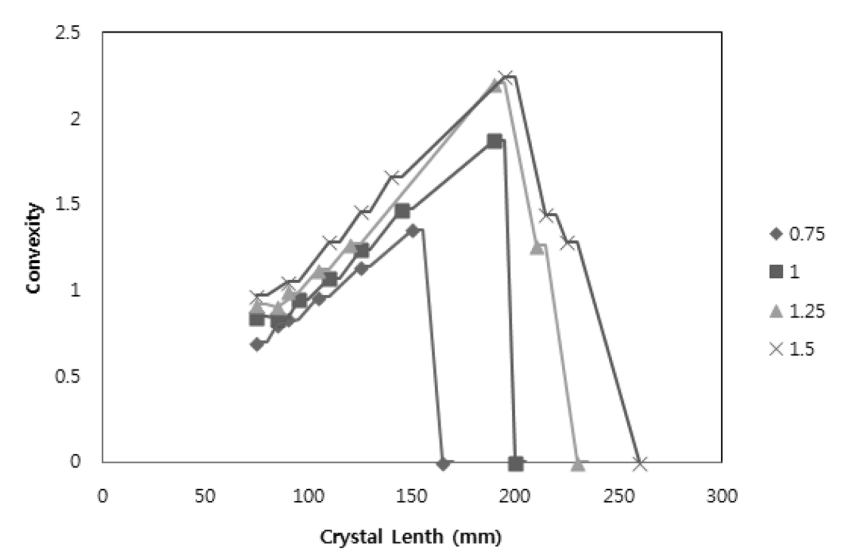

Fig. 7. Predicted evolutions of convexities as a function of crystal length.

$$
\mathrm{D}=\max Z_{\mathrm{h}}-\min Z_{\mathrm{h}}
$$

여기서 $\mathrm{Z}_{\mathrm{h}}$ 는 성장 방향으로의 계면의 높이를 나타낸다. 본 연구에서는 도가니의 형상이 서로 다른 모델의 convexity 를 정량적으로 비교하기 위해 $\mathrm{D}$ 를 각 모델에서 사용된 도가니의 반지름 $(\mathrm{R})$ 으로 나누어 일반화 하였으며 이를 결정의 수직방향 길이에 따라 비교하였다(Fig. 7). 실험 에 사용된 모든 모델에서 결정 계면의 convexity는 결정 성장이 도가니의 바닥에 가까워 질 때까지 계속해서 증가 하다가 성장 말기에 가까워지면 급격하게 감소하는 결과 를 보였다. 특히 h/d가 0.75 인 모델에서 계면의 convexity 가 가장 완만한 것으로 나타났으며, $\mathrm{h} / \mathrm{d}$ 가 커질수록 계 면의 convexity가 증가했다. 따라서 도가니 형상의 종횡 비를 1 이하로 작게 할수록 결정성장이 진행 되는 동안 비교적 완만한 형태의 고/액 계면을 유지하며 안정적인 성장거동을 보일 것으로 예측되며, 최종적으로 얻어진 단결정의 전위밀도가 낮아질 것으로 생각된다.

\section{4. 결 론}

전산유동해석을 통해 $\mathrm{KY}$ 성장로 내의 도가니의 종횡비 가 용융 사파이어의 유동과 결정성장 거동에 미치는 영 향을 시뮬레이션 하였다. 결정성장이 진행 되는 동안 용 탕의 난류거동은 관찰되지 않았으며, 도가니의 종횡비와 무관하게 균일한 하나의 소용돌이가 형성되었다. 용융 $\mathrm{Al}_{2} \mathrm{O}_{3}$ 의 유동은 중력과 온도에 의한 밀도 차에 의해 자 연대류가 지배적이며, $\mathrm{Gr}$ 수를 계산한 결과 결정성장이 진행 되는 동안 층류를 유지할 것으로 예측했다. 도가니 의 종횡비가 커질수록 용탕의 유동형태는 원형에서 길쭉 한 타원형태로 바뀌었으며, 결정성장이 진행 되는 동안 계면의 convexity가 증가하였다. 용탕의 유동속도는 종 횡비가 1.25 일 때 가장 빠른 것으로 관찰 되었으며, 이 
는 종횡비가 약 1.25 인 경우 유동의 구동력인 온도구배 가 도가니의 형상에 의해 가장 큰 값을 가지며 유동 구 조가 구형에 가까워지기 때문인 것으로 판단된다. 또한 종횡비가 증가할수록 계면의 convexity가 증가하는 것은 도가니의 기하학 형상에 의해 수직방향의 온도구배가 줄 어들어 계면이 아래쪽으로 성장하려는 경향이 커지기 때 문인 것으로 보인다.

도가니의 종횡비가 0.75 일 때 계면의 형상이 균일하고 유동속도도 느려 단결정의 품질을 높이는데 유리할 것으 로 보이나, 성장 방향에서 수직한 면을 통해 잉곳을 채 취하는 사파이어 공정의 특성상 도가니의 종횡비를 너무 작게 하면 단결정의 크기를 대형화 하기에는 오히려 적 합하지 않다. 또한 도가니 내벽의 온도에 따른 각 성장 단계의 유동속도 차이와 convexity를 고려하면 도가니의 종횡비를 1 이상으로 크게 하는 것은 유동속도가 빠르 면서도 convexity를 크게 하여 단결정의 품질을 떨어뜨 리는 결과를 가져온다. 그러므로 최종 단결정 잉곳의 품 질과 크기를 모두 고려하면 공정 특성 및 전체 $\mathrm{KY}$ 성 장로의 설계 특성에 맞추어 도가니의 종횡비를 $0.75 ~ 1.0$ 사이로 하는 것이 가장 적당할 것으로 판단된다.

\section{감사의 글}

본 연구는 한국생산기술연구원의 지원을 통해 이루어 졌으며 이에 감사드립니다.

\section{참 고 문 헌}

[1] A. Wang, G. Pickrell and R. May, Single-Crystal Sapphire Optical Fiber Sensor Instrumentation, Virginia Polytechnic Institute (US) Technical Report Chap. 3 (2002).
[2] J.K. Kang and Y.J. Kim, "Fabrication and characterization of tilted R-plane sapphire wafer for nonpolara-plane GaN", Journal of the Korean Crystal Growth and Crystal Technology 21(5) (2011) 187.

[3] Chandra P. Khattak and Frederick Schmid, "Growth of the world's largest sapphire crystals", Journal of Crystal Growth 225 (2001) 572.

[4] S.E. Demina, E.N. Bystrova, M.A. Lukanina, V.M. Mamedov, V.S. Yuferev, E.V. Eskov, M.V. Nikolenko, V.S. Postolov and V.V. Kalaev, "Numerical analysis of sapphire crystal growth by the Kyropoulos technique", Optical Materials 30 (2007) 62.

[ 5 ] S.J. Lim, H.Y. Shin, J.H. Kim and J.I. Im, "Finite element analysis for czochralski growth process of sapphire single crystal", Journal of the Korean Crystal Growth and Crystal Technology 21(5) (2011) 193.

[6] C.-H. Chen, J.-C. Chen, C.-W. Lu and C.-M. Liu, "Numerical simulation of heat and fluid flows for sapphire single crystal growth by the Kyropoulos method", Journal of Crystal Growth 318 (2011) 162.

[ 7 ] W.J. Lee, Y.C. Lee, H.H. Jo and Y.H. Park, "Effect of crucible geometry on melt convection and interface shape during Kyropoulos growth of sapphire single crystal", Journal of Crystal Growth 324 (2011) 248.

[ 8 ] A.T. Kuliev, N.V. Durnev and V.V. Kalae, "Analysis of 3D unsteady melt flow and crystallization front geometry during a casting process for silicon solar cells", Journal of Crystal Growth 303 (2007) 236.

[9] C.-W. Lu, J.-C. Chen, C.-H. Chen, C.-H. Chen, W.-C. Hsu and C.-M. Liu, "Effects of RF coil position on the transport processes during the stages of sapphire Czochralski crystal growth", Journal of Crystal Growth 312 (2010) 1074

[10] FluentInc., Fluent 12.0 Theory Guide, Pennsylvania: Canonsburg (2009)

[11] FluentInc., Fluent 12.0 User's Guide, Pennsylvania: Canonsburg (2009).

[12] White, Frank M., Viscous fluid flow, New York, McGraw-Hill (1991).

[13] J.C. Chen and C.W. Lu, "Influence of the crucible geometry on the shape of the melt-crystal interface during growth of sapphire crystal using a heat exchanger method", J. Crystal Growth 266 (2004) 239. 